\title{
Knowledge and attitudes of Croatian Dentists Regarding Antibiotic Prescription in Endodontics: A Cross-sectional Questionnaire-based Study
}

\section{Znanje i stajališta doktora dentalne medicine u Hrvatskojo propisivanju antibiotika u endodonciji: presječno istraživanje}

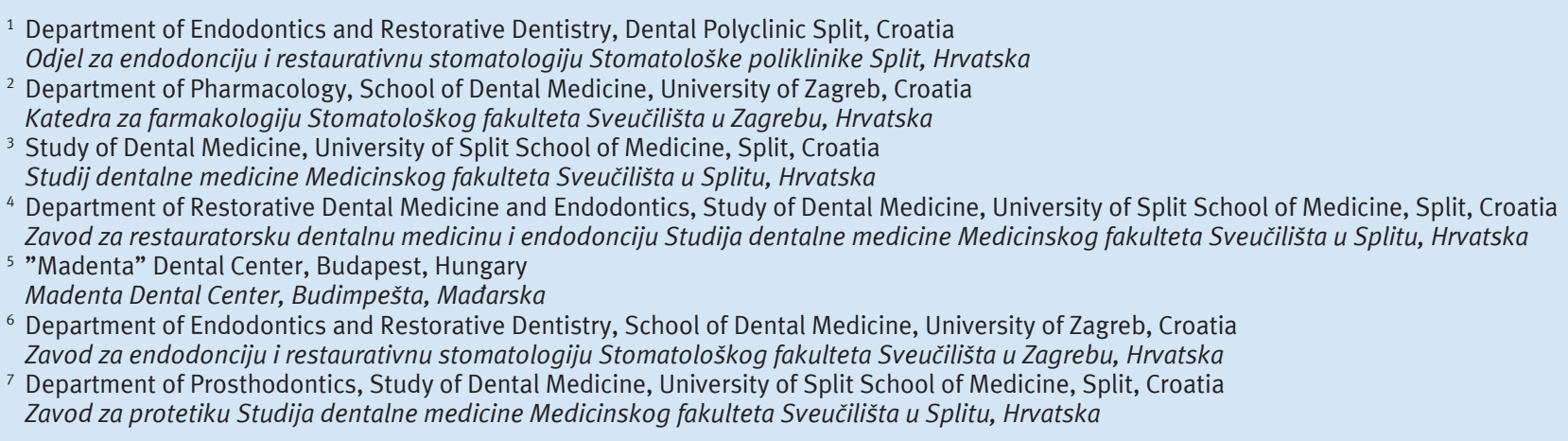

\section{Abstract}

Objectives: To assess dentists' level of knowledge and practice concerning antibiotic usage in endodontics using the European Society of Endodontology position statement as a reference. Material and Methods: A cross-sectional study was conducted in the form of an electronic questionnaire consisting of 23 questions, including dentists' demographic and professional characteristics, attitudes as well as experiences regarding antibiotics in endodontics. Data were evaluated by the Mann-Whitney test or the Kruskal Wallis 1-way ANOVA, $\alpha=5 \%$. Results: The overall mean self-reported knowledge of antibiotics usage in endodontics was $11.7 \pm 2.5$ points, out of a maximum possible score of 23 . The factors associated with a higher knowledge were: age $(P \leq 0.001)$, clinical experience $(P \leq 0.001)$, specialist training $(P=0.008)$, and adherence to the guidance on the use of systemic antibiotics in endodontics $(P=0.006)$. Dentists who specialized in endodontics $(16.1 \pm 2.2)$ achieved higher levels of knowledge. Conclusion: Knowledge on antibiotic usage in endodontics among dentists in Croatia is insufficient. There is a need for continuing education on the use of antibiotics among general dentists.
Received: August 22, 2021

Accepted: November 11, 2021

Address for correspondence Antonija Tadin

University of Split, School of Medicine

Study of Dental Medicine

Department of Restorative Dental

Medicine and Endodontics

Soltanska 2, 21000 Split, Croatia,

Phone: +38598609191

Fax: +38521557624

atadin@mefst.hr, dr.antonija.tadin@ gmail.com

ORCID ID: 0000-0002-5365-9816

MeSH terms: Dentists; Endodontics; Anti-Bacterial Agents; Health Knowledge Attitudes Practice Author keywords: Antibiotics; Knowledge; Questionnaire

\section{Introduction}

Most endodontic infections, likewise other odontogenic infections, have a polymicrobial origin, involving gram-positive, gram-negative, and strict or facultative anaerobic bacteria (1). Most endodontic infections are located within the tooth and can be solved by root canal treatment, drainage, or tooth extraction, without the need for local or systemic antibiotics (2). Antibiotics should be used as an adjunct in treat-
Uvod

Endodontske infekcije, kao i ostale odontogene zaraze, uglavnom su polimikrobnog podrijetla, uključujući grampozitivne, gram-negativne i stroge ili fakultativne anaerobne bakterije (1). Većina endodontskih infekcija nalazi se unutar zuba i može se riješiti liječenjem korijenskog kanala, drenažom ili ekstrakcijom zuba, bez upotrebe lokalnih ili sistemskih antibiotika (2). Antibioticima se treba koristiti kao 
ing apical periodontitis and only in cases of acute apical abscess with systematic involvement, when an infection is fast progressing, or in immunocompromised patients (3-7). In healthy patients, bacteremia caused by root canal treatment is transient and does not cause complications (8). The use of antibiotics is contraindicated in irreversible pulpitis, pulp necrosis, chronic apical periodontitis and localized apical periodontitis (9). Previous studies have reported that antibiotics do not reduce the pain or swelling arising in non-vital symptomatic teeth in the absence of systematic involvement $(4,5)$. On the other hand, the patients with life-threatening conditions such as swelling of the floor of the mouth or breathing difficulties should be hospitalized and treated by administering intravenous antibiotics (7).

Since the microbial samples are not routinely taken from infected root canals, antibiotics are usually prescribed empirically, which consequently leads to their over-prescription (7). Antibiotic overuse and prescription of inappropriate antibiotics (misuse) have been the leading cause of increased microbial resistance (10). It has been estimated that over 25 , 0000 antibiotic-resistant infection cases per year are being diagnosed in the United States, of which 23,000 are lethal (11). Another aspect in the context of health-care consequences of antibacterial resistance includes health complications requiring higher treatment needs and hospital costs $(1,12)$. Furthermore, overuse and misuse of antibiotics can increase the risk of developing potentially fatal side effects or anaphylactic reactions $(3,13,14)$.

Although dentists are accountable for approximately $10 \%$ of the overall antibiotic prescriptions, their influence on the development of resistant bacterial species is not negligible (3). Also, the problem of increased antibiotic prescribing has arisen in recent years (15). Another critical issue is the use of antibiotic prophylaxis in medically compromised patients undergoing endodontic therapy. Although there are many controversies in the literature regarding this issue, antibiotic prophylaxis is still necessary in cases when the benefits have been clearly demonstrated $(7,16)$. Therefore, in 2018, the European Society of Endodontology (ESE) issued detailed guidelines on antibiotic prescribing (17). However, despite the existing guidelines, the validity of antibiotic prescribing in practice, as well as the level of adherence to the current recommendations remains unclear $(12,18)$.

The purpose of this study was to investigate the knowledge and attitudes of Croatian dentists regarding antibiotic prescription practice in endodontics by relying on the ESE recommendations.

\section{Material and methods}

This online cross-sectional study was conducted between January and March 2020 among dentists working in Croatia. The study was conducted in full accordance with the ethical principles, including the World Medical Association Declaration of Helsinki (version 2008), and was approved by the Ethics Committee of the University of Split School of Medicine, Split, Croatia (No: 003-08/20-03/0005). dodatkom u liječenju apikalnog parodontitisa $\mathrm{i}$ to samo $\mathrm{u}$ slučaju akutnoga apikalnoga apscesa sa sustavnim širenjem kada infekcija brzo napreduje ili ako je pacijent imunokompromitiran $(3-7)$. Kod zdravih bolesnika je bakterijemija prouzročena liječenjem korijenskog kanala prolazna i ne izaziva komplikacije (8). Primjena antibiotika je kontraindicirana u slučaju ireverzibilnog pulpitisa, nekroze pulpe, kroničnoga apikalnog parodontitisa i lokaliziranoga apikalnog parodontitisa (9). U dosadašnjim studijama istaknuto je da antibiotici ne smanjuju bol ili oteklinu koja nastaje u avitalnim simptomatskim zubima kada nema sustavnoga širenja $(4,5)$. S druge strane, za život opasna stanja, poput otekline dna usta ili poteškoće s disanjem, zahtjevaju hospitalizaciju i liječenje aplikacijom antibiotika intravenski (7).

Budući da se mikrobni uzorci ne uzimaju rutinski iz inficiranih korijenskih kanala, antibiotici se obično propisuju empirijski, što posljedično rezultira njihovim pretjeranim propisivanjem (7). Prekomjerna upotreba antibiotika i propisivanje onih neodgovarajućih (zlouporaba) glavni su uzroci povećane rezistencije mikroba (10). Procjenjuje se da se u Sjedinjenim Američkim Državama na godinu dijagnosticira više od 250000 slučajeva infekcija otpornih na antibiotike, od kojih 23000 završi sa smrtim ishodom (11). Drugi aspekt u kontekstu zdravstvenih posljedica antibakterijske rezistencije obuhvaća zdravstvene komplikacije koje zahtijevaju veću potrebu za liječenjem i bolničke troškove $(1,12)$. Nadalje, prekomjerna primjena antibiotika i njihova zlouporaba povećavaju rizik od pojave potencijalno smrtonosnih nuspojava ili anafilaktičnih reakcija $(3,13,14)$.

Iako su doktori dentalne medicine odgovorni za otprilike $10 \%$ ukupnih propisanih antibiotika, njihov utjecaj na razvoj rezistentnih vrsta bakterija nije zanemariv (3). Posljednjih se godina također pojavio problem $s$ povećanim propisivanjem antibiotika (15).

Drugo važno pitanje jest uporaba antibiotičke profilakse u slučaju medicinski kompromitiranih pacijenata koji su podvrgnuti endodontskoj terapiji. Iako u literaturi postoje mnogobrojne kontroverzije u vezi s tim pitanjem, antibiotička profilaksa i dalje je prijeko potrebna kada postoje jasni dokazi za njezinu dobrobit $(7,16)$. Zato je Europsko endodontsko društvo 2018. godine dalo detaljne smjernice o propisivanju antibiotika (17). No, unatoč tomu i dalje je nejasna valjanost propisivanja antibiotika u praksi i razina poštovanja postojećih preporuka $(12,18)$.

Svrha ovog istraživanja bila je ispitati znanje i stajališta hrvatskih doktora dentalne medicine o propisivanju antibiotika u endodonciji oslanjajući se na preporuke Europskoga endodontskoga društva.

\section{Materijal i metode}

Ova presječna studija provedena je od siječnja do ožujka 2020. godine među doktorima dentalne medicine koji rade u Republici Hrvatskoj. Potpuno je u skladu s etičkim načelima, uključujući Helsinšku deklaraciju Svjetske liječničke udruge (verzija iz 2008. godine), a odobrilo ju je Etičko povjerenstvo Medicinskoga fakulteta Sveučilišta u Splitu (No: 003-08/20-03/0005). 
An online questionnaire consisting of three parts was designed specifically for this study. The first part included dentists' socio-demographic and general characteristics such as age, gender, years of experience, education level, clinical setting, specialization and the number of patients treated a day. The second part of the questionnaire comprised ten multiple-choice questions (MCQs) concerning the use of antibiotics in endodontics. These questions referred to the usage of antibiotics in endodontics by the European Society of Endodontology (17). Five items were conventional MCQs with only one correct answer, while other five items were with several correct answers. Each correct answer was scored with one point, while incorrect answers were scored with zero. The total knowledge score was calculated as the sum of all correct answers, with a maximum overall knowledge score of 23 points. Overall knowledge per participant was categorized, using the Bloom's cut-off point, with "good" representing 80 to $100 \%$ (16.8-23 points), "moderate" if the score was from 60 to $79 \%$ (12.6-16.7 points), and "poor" if the overall score was less than $60 \%$ of the maximum score ( $\leq 12.5$ points) (19). The third part of the questionnaire included questions about participant's personal experiences, attitudes, and self-assessed knowledge about the use of antibiotics in endodontics.

Firstly, the experts in different dental fields (three endodontists and one pharmacologist) reviewed the draft version of the questionnaire and agreed on the final suitability. A pilot study including 100 dentists was conducted as part of a graduation thesis at the Study of Dental Medicine, University of Split School of Medicine. The data obtained from the pilot study were not included in the analyses. The final questionnaire was adapted based on the data obtained from the pilot study, and it was sent to ten dentists for feedback, who reported having no difficulty in completing the test. The online questionnaire was generated using a Google Docs form and was sent to the legal administrative staff of the Croatian Dental Chamber (CDC) for approval. The CDC staff then shared the link to the questionnaire to all dentists on their official mailing list.

Participation in the study was voluntary, anonymous, and without compensation. All participants were informed about the rationale and the aim of the study. The online form first displayed information about the scope of the study that dentists had to go through before moving forward to the questionnaire. Completing the questionnaire was considered to be consent for participation. In order to be included in the study, dentists had to work in clinical practice with minimum one year experience, and the membership in the CDC.

The study was reported to be in accordance with the STROBE reporting checklist (20).

The minimum required sample size $(\mathrm{n}=337)$ was calculated by considering the total number of dentists who worked in clinical practice $(\mathrm{n}=2743)$, a population proportion of $50 \%$, and a $95 \%$ confidence interval (21). All answers from the online form were automatically imported in an Excel file (Ver. Office 2007, Microsoft Corporation, Redmond, WA, USA) and were then coded appropriately for the analyses. The results were first analyzed using descriptive statistics. The
Internetski upitnik sastavljen od triju dijelova posebno je pripremljen za ovu studiju. Prvi dio obuhvaća sociodemografske i opće značajke doktora dentalne medicine, kao što su dob, spol, godine iskustva, stupanj obrazovanja, kliničko okružje, specijalizacija i broj liječenih pacijenata na dan. Drugi dio upitnika sastoji se od deset pitanja s višestrukom mogućnošću odgovora (engl. Multiple Choice Questions - MCQ) o primjeni antibiotika u endodonciji. Ta se pitanja referiraju na preporuke Europskoga endodontološkoga društva o primjeni antibiotika u endodonciji (17). Pet pitanja bila su ona uobičajena za višestruki tip odgovora sa samo jednim točnim odgovorom, a ostalih pet omogućivalo je nekoliko točnih odgovora. Svaki točan odgovor bodovan je jednim bodom, a netočni nulom. Ukupni rezultat za znanje izračunan je kao zbroj svih točnih odgovora, pri čemu je maksimalna ukupna ocjena za znanje bila 23 boda. Sveukupno znanje svakoga sudionika kategorizirano je korištenjem Bloomove granične točke, pri čemu "dobro" znači 80 do $100 \%$ (16,8 - 23 boda), "umjereno" 60 do 79 \% (12,6 - 16,7 bodova) i "loše" ako je ukupan rezultat manji od $60 \%$ maksimalnog rezultata ( $\leq 12,5$ bodova) (19). Treći dio upitnika bila su pitanja o osobnim iskustvima, stajalištima i samoprocijenjenoj razini znanja sudionika o primjeni antibiotika u endodonciji.

Najprije su stručnjaci iz područja dentalne medicine (tri specijalista endodoncije i jedan stručnjak iz područja farmakologije) pregledali nacrt upitnika i dogovorili se o konačnoj primjerenoj verziji upitnika. U sklopu diplomskoga rada na Studiju dentalne medicine Medicinskoga fakulteta Sveučilišta u Splitu provedeno je pilot-istraživanje na 100 stomatologa. Podatci dobiveni iz te studije nisu uključeni u analize. Konačni upitnik prilagođen je na temelju podataka dobivenih iz pilot-studije i poslan desetorici doktora dentalne medicine zbog povratne informacije, no oni nisu imali poteškoća s njegovim ispunjavanjem. Online upitnik generiran je s pomoću obrasca Google Docs i poslan na odobrenje pravnome administrativnom osoblju Hrvatske komore dentalne medicine (HKDM). Zatim je putem svoje službene mailing liste HKDM podijelilo poveznicu na upitnik svim doktorima dentalne medicine.

Sudjelovanje u istraživanju bilo je dobrovoljno, anonimno i bez naknade. Svi sudionici obaviješteni su o pojedinostima i ciljevima istraživanja. Online obrazac najprije je prikazivao informacije s opisom studije koji su doktori dentalne medicine morali pročitati prije nego što su prešli na upitnik. Ispunjavanje upitnika smatralo se pristankom za sudjelovanje. Za uključenje u studiju doktori dentalne medicine morali su imati barem godinu dana iskustva u kliničkoj praksi te članstvo u HKDM-u. Izvještaj o provedenoj studiji napisan je u skladu sa smjernicama za izvještavanje opažajnih studija STROBE (20).

Minimalna veličina uzorka $(\mathrm{n}=337)$ izračunana je uzimajući u obzir ukupan broj doktora dentalne medicine koji rade u kliničkoj praksi $(\mathrm{n}=2743)$, udio populacije od $50 \%$ i interval pouzdanosti od $95 \%$ (21). Svi odgovori iz online obrasca automatski su uneseni u datoteku Excela (Ver. Office 2007, Microsoft Corporation, Redmond, WA, SAD) i primjereno kodirani za statističku obradu. Rezultati su najprije analizirani deskriptivnom statistikom. Kolmogorov-Smir- 
Kolmogorov-Smirnov test evaluated compliance with the normal distribution of the dependent variable. Means and standard deviations were calculated for quantitative variables, while percentages and absolute numbers were used for presenting qualitative variables. Statistical analyses were conducted using the Mann-Whitney test or the Kruskal Wallis 1-way ANOVA. To account for possible confounding, multiple regression analysis was used to determine a relationship between selected independent variables (age, gender, working experience, specialist training, number of patients treated a day, attending a lecture regarding antibiotics in endodontics and knowledge regarding guidance on the use of systemic antibiotics in endodontics) with the knowledge score (dependent variable). The level was set at 5\%. All statistical analyses were carried out using the IBM SPSS Statistics, version 25 (SPSS, IBM Corp, Armonk, New York, USA).

\section{Results}

A total of 657 dentists working in Croatia participated in this study (23.96\% response rate). The demographic and professional characteristics of the participants are presented in Table 1. The majority (96.5\%) of the participants who responded worked in primary care and most of them were females $(71.5 \%)$. The mean age $( \pm \mathrm{SD})$ of the participants was $41.86 \pm 11.54$ years, with $14.02 \pm 10.98$ years of working experience.

The overall mean knowledge score regarding antibiotics use in endodontics was $11.7 \pm 2.5$ points. There were no significant differences between genders $(P=0.567)$, with mean values for male and female dentists being $11.6 \pm 2.5$ and $11.7 \pm 2.5$, respectively. There was a significant difference $(P<0.001)$ in knowledge scores between specialists $(12.6 \pm 2.8)$ and general practitioners $(11.6 \pm 2.5)$, with endodontic specialists scoring the highest $(P=0.021)$. There was a significant difference in knowledge scores $(P \leq 0.001)$, suggesting a slight decrease in knowledge regarding years of work experience, with the highest scores observed among participants working from 0 to 5 years $(12.1 \pm 2.5)$, compared to those working either from 6 to 10 years $(11.3 \pm 2.6)$ or from 11 to 20 years (11.1 \pm 2.3$)$.

Table 2 shows the distribution of correct answers to the questions regarding antibiotics use in endodontics. Only $2.0 \%(\mathrm{n}=13)$ of the surveyed dentists knew that Penicillin VK is a beta-lactam antibiotic, which is the first line of antibiotics chosen as adjunct therapeutic agents in endodontic infection in a healthy patient with no medical allergies. Also, only $17.2 \%(n=113)$ of them gave the same answers for Amoxicillin. Most of the dentists answered (94.5\%, $\mathrm{n}=621)$ that endodontic surgery is a procedure that requires administration of prophylactic antibiotics to prevent infective endocarditis. In contrast, only $27.1 \%(n=178)$ of them stated that periodontal ligament (intraligamentary) anesthesia requires the same approach.

The answers regarding antibiotic prescription in endodontics are presented in Table 3. A higher level of knowledge was observed in dentists who reported being informed about guidelines on the use of systemic antibiotics in end- novljev test korišten je za procjenu usklađenosti $s$ normalnom distribucijom zavisne varijable. Za kvantitativne varijable izračunane su srednje vrijednosti i standardne devijacije, a za prikaz kvalitativnih varijabli korišteni su postotci i apsolutni brojevi. Statistička analiza obavljena je Mann-Whitneyjevim testom ili Kruskal-Wallisovom jednosmjernom ANOVA-om. Kako bi se objasnio utjecaj mogućih zbunjujućih čimbenika, multipla regresijska analiza korištena je za utvrđivanje odnosa između odabranih neovisnih varijabli (dob, spol, radno iskustvo, specijalizacija, broj liječenih pacijenata na dan, pohađanje predavanja o antibioticima u endodonciji i znanja o smjernicama o primjeni sistemskih antibiotika u endodonciji) i ocjene znanja (ovisna varijabla). Razina $\alpha$ postavljena je na $5 \%$. Sve statističke analize obavljene su u programu IBM SPSS Statistics, verzija 25 (SPSS, IBM Corp, Armonk, New York, SAD).

\section{Rezultati}

U studiji je sudjelovalo ukupno 657 doktora dentalne medicine (23,96 \% iznosila je stopa odgovora). Demografske i profesionalne značajke nalaze se u tablici 1 . Većina $(96,5$ $\%)$ ispitanika radila je u primarnoj zdravstvenoj zaštiti te su većina ispitanika bile žene $(71,5 \%)$. Srednja dob $( \pm S D)$ ispitanika bila je 41,86 $\pm 11,54$ godina, $s$ 14,02 $\pm 10,98$ godina radnoga staža.

Ukupan zbroj znanja svih ispitanika, $s$ obzirom na korištenje antibiotika u endodonciji, bio je 11,7 $\pm 2,5$ bodova. Nije uočena statistički značajna razlika s obzirom na spol $(P$ $=0,567$ srednje vrijednosti znanja za muškarce i žene iznosile su $11,6 \pm 2,5$ i $11,7 \pm 2,5$. Utvrđena je statistički značajna razlika $(P<0,001)$ u znanju između specijalista $(12,6 \pm 2,8)$ i općih doktora dentalne medicine $(11,6 \pm 2,5)$, s time da su specijalisti endodoncije pokazali najbolje znanje $(P=0,021)$. Također je ustanovljena statistički značajna razlika u zbroju znanja s obzirom na duljinu radnoga staža $(P \leq 0,001)$. Uočen je blagi pad znanja s godinama radnog iskustva, pri čemu su najbolji rezultati zabilježeni među sudionicima koji rade od 0 do 5 godina $(12,1 \pm 2,5)$, u usporedbi s onima koji rade od 6 do 10 godina $(11,3 \pm 2,6)$ ili od 11 do 20 godina $(11,1 \pm 2,3)$.

U tablici 2. je distribucija točnih odgovora na pitanja o primjeni antibiotika u endodonciji. Samo 2,0 \% $(n=13)$ ispitanih doktora dentalne medicine znalo je da je penicilin VK beta-laktamski antibiotik i da je prva linija antibiotika koja bi trebala biti izabrana kao pomoćno terapijsko sredstvo $\mathrm{u}$ endodontskoj infekciji kod zdravoga pacijenta bez medicinskih alergija. Također je samo 17,2 \% $(\mathrm{n}=113)$ doktora tako odgovorilo na amoksicilin. Većina doktora dentalne medicine odgovorila je $(94,5 \%, \mathrm{n}=621)$ da je endodontska kirurgija zahvat koji zahtijeva profilaktičnu primjenu antibiotika u prevenciji infektivnog endokarditisa. Suprotno tomu, samo je $27,1 \%(n=178)$ njih smatralo da parodontalna ligamentarna (intraligamentarna) anestezija zahtijeva isti pristup.

Odgovori o propisivanju antibiotika u endodonciji prikazani su u tablici 3. Viša razina znanja uočena je kod doktora dentalne medicine koji su naveli da su informirani o smjernicama o primjeni sistemskih antibiotika u endodonciji $(P=$ 
Table 1 Demographic and professional characteristic of dentists $(n=657)$

Tablica 1. Demografske i profesionalne karakteristike doktora dentalne medicine $(n=657)$

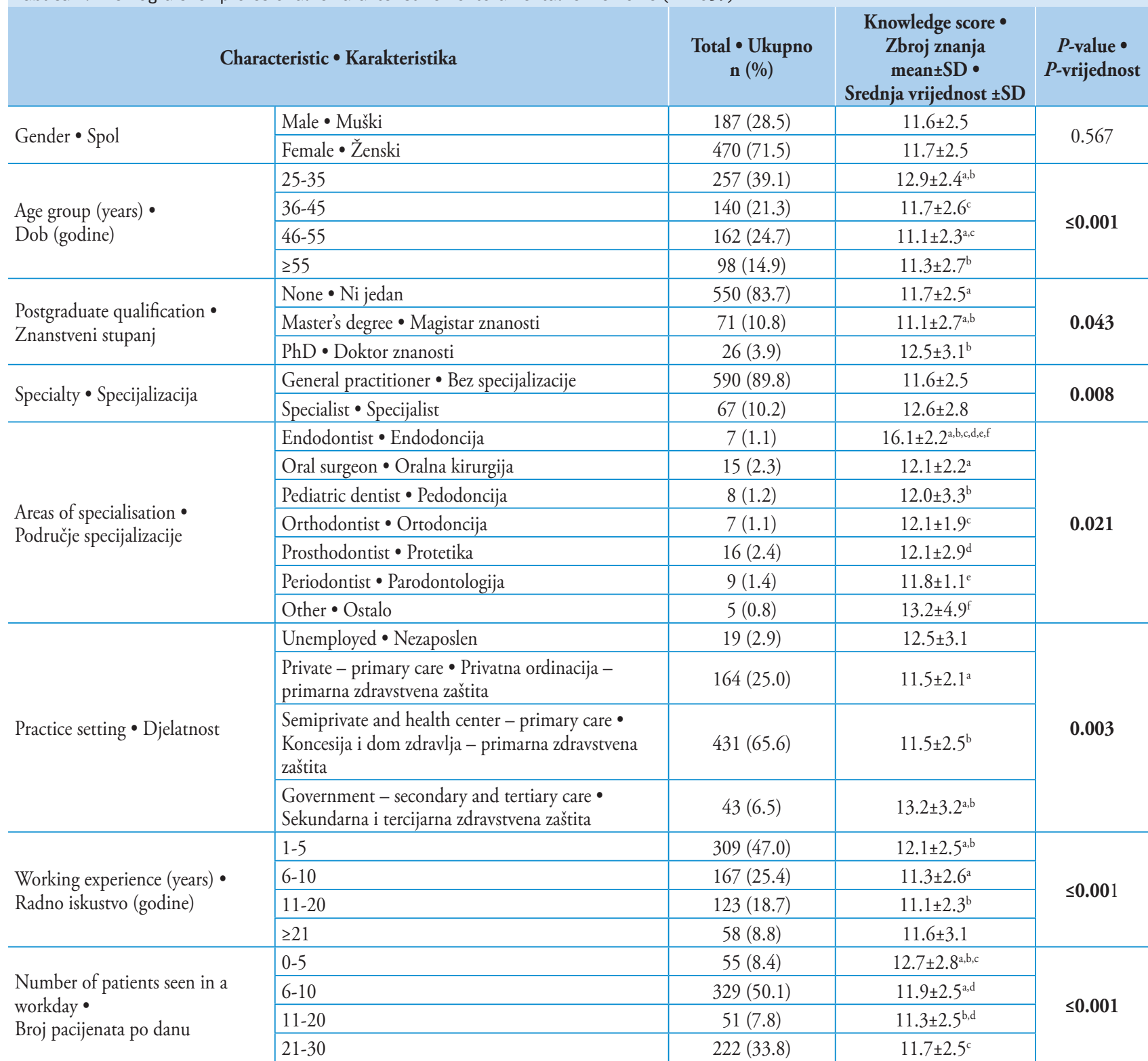

Data are presented as whole numbers and percentages or mean \pm SD. Podatci su prezentirani kako cijeli broj i postotak ili srednja vrijednost $\pm(S D)$. ${ }^{*}$ Statistical significance was tested by the Mann-Whitney test or Kruskal Wallis 1-way ANOVA. The same superscript lower letter indicated a statistical difference between groups based on post hoc test. Statistical significance was set to $\mathrm{p}<0.05$. $\bullet$ Statistička značajnost ispitana je Mann-Whitneyjevim ili Kruskal-Wallisovim jednosmjernim ANOVA testom. Isto slovo u superskriptu označava statistički značajnu razliku među grupama na temelju post hoc testa. Statistička značajnost bila je postavljena na $P<, 05$.

Abbreviation • Skraćenica: SD - standard deviation $\bullet$ standardna devijacija

odontics $(p=0.006)$. More than half of the participating dentists $(54.1 \%)$ claimed that their knowledge regarding the use of antibiotics in endodontics was good and very good.

The association of the dentists' knowledge about antibiotics use and their demographic data as possible predictors are presented in Figure 1. Knowledge was shown to be associated with dentists' age $(\beta=-0.539, \mathrm{SE}=0.187, P=0.004)$, specialization $(\beta=1.364, S E=0.324, P \leq 0.001)$, number of patients treated daily $(\beta=-0.363, \mathrm{SE}=0.130, P=0.005)$, and awareness about the available guidance on the use of systemic antibiotics in endodontics $(\beta=0.609, \mathrm{SE}=0.248, P=0.014)$.
0,006). Više od polovine stomatologa $(54,1 \%)$ svoje znanje o primjeni antibiotika u endodonciji okarakteriziralo je dobrim i vrlo dobrim.

Povezanost znanja doktora dentalne medicine o upotrebi antibiotika i njihovi demografski podatci kao mogući prediktori nalaze se na slici 1 . Pokazalo se da je znanje povezano $s$ dobi ispitanika $(\beta=-0,539, \mathrm{SE}=0,187, P=0,004)$, specijalizacijom $(\beta=1,364, S E=0,324, P \leq 0,001)$, brojem pacijenata koje liječe na dan $(\beta=-0,363, \mathrm{SE}=0,130, P=0,005)$ te upućenošću u smjernice o primjeni antibiotika u endodonciji $(\beta=0,609, \mathrm{SE}=0,248, P=0,014)$. 
Table 2 The frequency distribution (\%) of dentists' answers to the questions regarding antibiotics use in endodontics Tablica 2. Distribucija učestalosti (\%) odgovora doktora dentalne medicine na pitanja o primjeni antibiotika u endodonciji

\section{Question・ Pitanje}

When systemic antibiotics are indicated, which antibiotic would you choose for the treatment of an endodontic infection in an adult, healthy patient with no medical allergies? • Kada su indicirani sistemski antibiotici; koji biste antibiotik odabrali za liječenje endodontske infekcije za odrasloga, zdravoga pacijenta bez medicinskih alergija?

When systemic antibiotics are indicated, which antibiotic would you choose for the treatment of an endodontic infection in an adult, healthy patient with an allergy to Penicillin? • Kada su indicirani sistemski antibiotici; koji biste antibiotik odabrali za liječenje endodontske infekcije za odrasloga, zdravoga bolesnika s alergijom na penicilin?

For how many days would you prescribe antibiotics? $\bullet \mathrm{Na}$ koliko dana biste propisivali antibiotike?

If prescribed 1st line antibiotic is not practical in 48-72 h, what would you do? $\bullet$ Ako propisani antibiotik prve linije nije djelotvoran za 48 do 72 sata, što biste učinili?

In which of the following situations do you consider that antibiotics are indicated? $\bullet U$ kojoj od sljedećih situacija smatrate da su antibiotici indicirani?

When is antibiotic prophylaxis indicated, in which of the following medical conditions would you prescribe before endodontic surgery? $\bullet$ Kada je indicirana antibiotička profilaksa; u kojemu od sljedećih zdravstvenih stanja biste je propisali prije endodontske operacije?

\section{Answer • Odgovor}

Tetracyclines $\bullet$ Tetraciklin

Azithromycin $\bullet$ Azitromicin

Erythromycin $\bullet$ Eritromicin

Clindamycin $\bullet$ Klindamicin

Amoxicillin with clavulanic acid $\bullet$ Amoksicilin $s$ klavulanskom kiselinom

Cephalosporins $\bullet$ Cefalosporin

Metronidazole $\bullet$ Metronidazol

Clarithromycin $\bullet$ Klaritromicin

Penicillin $V \bullet$ Penicillin $V$

Amoxicillin $\bullet$ Amoksicilin

Ciprofloxacin $\bullet$ Ciprofloksacin

Tetracyclines $\bullet$ Tetraciklin

Azithromycin $\bullet$ Azitromicin

Erythromycin $\bullet$ Eritromicin

Clindamycin $\bullet$ Klindamicin

Amoxicillin with clavulanic acid $\bullet$ Amoksicilin s klavulanskom kiselinom

Cephalosporins $\bullet$ Cefalosporini

Metronidazole $\bullet$ Metronidazol

Clarithromycin $\bullet$ Klaritromicin

Penicillin V • Penicillin V

Amoxicillin $\bullet$ Amoksicilin

Ciprofloxacin $\bullet$ Ciprofloksacin

Total $\bullet$

Ukupno

n (\%)

$2(0.3)$

$0(0)$

$2(0.3)$

$38(5.8)$

$481(73.2)$

$1(0.2)$

$7(1.1)$

$0(0)$

$13(2.0)$

$113(17.2)$

$0(0)$

$3(0.5)$

$11(1.7)$

$47(7.2)$

$547(83.3)$

3-7 day $\bullet 3-7$ dana

5-10 days $\bullet$ 5-10 dana

$2(0.3)$

$26(4.0)$

$10(1.5)$

$4(0.6)$

$0(0)$

$2(0.6)$

$3(0.5)$

$209(31.8)$

$191(29.1)$

Patient need to use all antibiotics from the prescribed package $\bullet$ Pacijent se $257(39.1)$

treba koristiti svim antibioticima iz propisanog pakiranja

\begin{tabular}{l|l} 
Prescribe an additional antibiotic - Metronidazole $\bullet$ Prepisati dodatni antibiotik - & 389 (79.9)
\end{tabular} Metronidazol

Refer to specialist $\bullet$ Javiti se specijalistu

Extraction $\bullet$ Vađenje zuba

Other $\bullet$ Ostalo

$35(5.3)$

$3(0.6)$

Symptomatic irreversible pulpitis $\bullet$ Simptomatski ireverzibilni pulpitis

$70(14.4)$

Pulp necrosis $\bullet$ Nekroza pulpe

$1(0.2)$

Symptomatic apical periodontitis $\bullet$ Simptomatski apikalni parodontitis

$3(0.5)$

Acute apical abscess with systemic involvement $\bullet$ Akutni apikalni apsces sa sistem$5(0.8)$ skom uključenošcu

Acute apical abscess without systemic involvement $\bullet$ Akutni apikalni apsces bez sistemske uključenosti

Chronic apical periodontitis with sinus tract $\bullet$ Kronični apikalni parodontistis sa sinus traktom

Impaired immunologic function $\bullet$ Oslabljena imunosna funkcija

Prosthetic joint replacement $\bullet$ Umjetni zglobovi

$\begin{array}{ll}\text { Patients whose jawbones are exposed to high-dose irradiation } • \text { Pacijenti cije su kosti } & 265 \text { (40.3) }\end{array}$ lica bile izložene visokim dozama zračenja

Patients receiving intravenous bisphosphonate treatment $\bullet$ Pacijenti koji primaju intravensku terapiju bisfosfonatima

Patients with cyanotic congenital heart disease $\bullet$ Pacijenti s cijanoticnom prirodenom srčanom bolešcu

Patients with noncyanotic congenital heart disease $\bullet$ Pacijenti s necijanotičnom prirođenom srčanom bolešću

Patients with high blood pressure $\bullet$ Pacijenti s visokim krvnim tlakom

Patients with liver disease $\bullet$ Pacijenti $s$ bolestima jetre
$554(82.8)$

$92(14.0)$

$13(2.0)$

$455(69.2)$

$380(57.8)$

$186(28.3)$

379 (77.8)

107 (22.0)

$3(0.4)$

13(1.9) 
When is antibiotic prophylaxis indicated, in which of the following dental procedures would you prescribe it? - Kada je indicirana antibiotička profilaksa; u kojemu od sljedećih stomatoloških zahvata biste je propisali?
In an adult, healthy patient with no medical allergies, with irreversible pulpitis, to avoid the occurrence of postoperative complications (pain, swelling), do you consider it necessary to prescribe antibiotics before endodontic instrumentation? • Smatrate li da je potrebno kod odrasloga, zdravoga pacijenta bez medicinskih alergija, ali s ireverzibilnim pulpitisom, propisati antibiotike prije endodontske instrumentacije kako bi se izbjegle postoperativne komplikacije (bol, oteklina).

In an adult, healthy patient with no medical allergies, with pulp necrosis, to avoid the occurrence of postoperative complications (pain, swelling), do you consider it necessary to prescribe antibiotics before endodontic instrumentation? • Smatrate li da je potrebno kod odrasloga, zdravoga pacijenta bez medicinskih alergija, ali s nekrozom pulpe, prije endodontske instrumentacije propisati antibiotike kako bi se izbjegle postoperativne komplikacije (bol, oteklina).

In an adult, healthy patient with no medical allergies, with chronic apical periodontitis, to avoid the occurrence of postoperative complications (pain, swelling), do you consider it necessary to prescribe antibiotics before endodontic instrumentation? • Smatrate li da je potrebno kod odrasloga, zdravoga pacijenta bez medicinskih alergija, ali $s$ kroničnim apikalnim parodontitisom, prije endodontske instrumentacije propisati antibiotike kako bi se izbjegle postoperativne komplikacije (bol, oteklina).

\begin{tabular}{|c|c|}
\hline Supraperiosteal injection $\bullet$ Supraperiostalna injekcija & $36(5.5)$ \\
\hline $\begin{array}{l}\text { Periodontal ligament (Intraligamentary) injection • Injekcija u parodontni liga- } \\
\text { ment (intraligamentarna anestezija) }\end{array}$ & $178(27.1)$ \\
\hline An alveolar nerve block injection • Blokada alveolarnoga živca & $64(9.7)$ \\
\hline $\begin{array}{l}\text { Endodontic access opening of teeth with vital pulpal tissues } \bullet \text { Trepanacija zuba } s \\
\text { vitalnim pulpnim tkivom }\end{array}$ & $85(12.9)$ \\
\hline $\begin{array}{l}\text { Endodontic access opening of teeth with necrotic pulpal tissues } \bullet \text { Trepanacijski } \\
\text { otvor } s \text { nekrotičnim pulpnim tkivom }\end{array}$ & $16(2.4)$ \\
\hline $\begin{array}{l}\text { Endodontic instrumentation and obturation } \bullet \text { Endodontska instrumentacija } i \\
\text { punjenje korijenskog kanala }\end{array}$ & $170(25.8)$ \\
\hline $\begin{array}{l}\text { Retreatment of root canal filling of an asymptomatic tooth without signs of periapi- } \\
\text { cal periodontitis on X-ray } \bullet \text { Ponovno liječenje (revizija) asimtomatskoga zuba bez } \\
\text { znakova periapikalnoga parodontitisa na RTG snimkamai }\end{array}$ & $13(2.7)$ \\
\hline $\begin{array}{l}\text { Retreatment of the root canal filling of an asymptomatic tooth with the presence of } \\
\text { signs of periapical periodontitis on X-ray } \bullet \text { Ponovno lijecenje (revizija) asimtomat- } \\
\text { skoga zuba sa znakovima periapikalnoga parodontitisa na RTG snimkama }\end{array}$ & $85(17.5)$ \\
\hline $\begin{array}{l}\text { Retreatment of root canal filling of the symptomatic tooth (pain) with the presence of } \\
\text { signs of periapical periodontitis on X-ray } \bullet \text { Ponovno liječenje (revizija) simptomat- } \\
\text { skoga zuba (bolan) sprisutnosću periapikalnoga parodontitisa na RTG snimkama }\end{array}$ & $203(41.7)$ \\
\hline Endodontic surgery $\bullet$ Endodontska kirurgija & $621(94.5)$ \\
\hline $\mathrm{No} \bullet \mathrm{Ne}$ & $648(98.8)$ \\
\hline Yes $\bullet \mathrm{Da}$ & $9(1.3)$ \\
\hline $\mathrm{No} \bullet \mathrm{Ne}$ & $644(98.0)$ \\
\hline Yes $\bullet \mathrm{Da}$ & $13(2.0)$ \\
\hline$N o \bullet \mathrm{Ne}$ & $609(92.7)$ \\
\hline Yes $\bullet \mathrm{Da}$ & $48(7.3)$ \\
\hline
\end{tabular}

Data are presented as whole numbers and percentages. Correct answers are italicized. • Podatci su prikazani kao cijeli brojevi i postotci. Točni odgovori napisani su kurzivom.

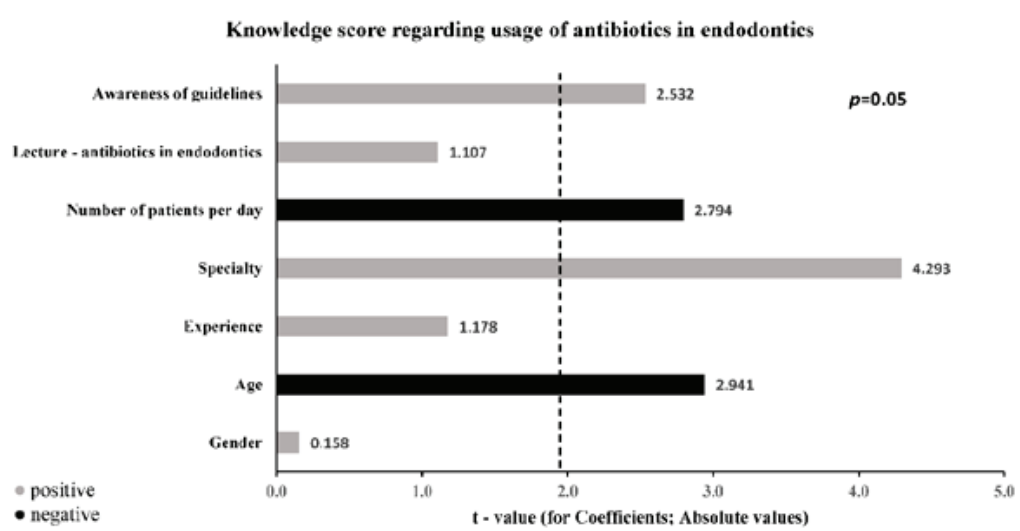

Figure 1 Multiple linear regression analysis. Significant dependence of measured knowledge with participant demographic data and attitudes toward the usage of antibiotics in endodontics as possible predictors.

Slika 1. Multipla linearna regresijska analiza; značajna povezanost izmjerenog znanja ispitanika s njihovim demografskim podatcima i stajalištima s obzirom na korištenje antibiotika u endodonciji 
Table 3. Attitudes of dentists toward antibiotic prescribing in endodontics

Tablica 3. Stajališta doktora dentalne medicine prema propisivanju antibiotika u endodonciji

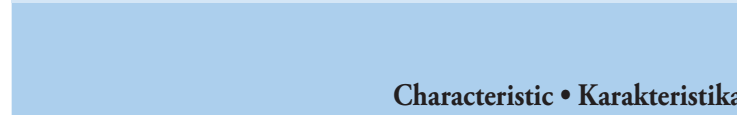

\section{Characteristic $\bullet$ Karakteristika}

Attending at least one lecture relating to the use of antibiotics in endodontics during the last three years Slušali ste barem jedno predavanje o primjeni antibiotika u endodonciji tijekom posljednje tri godine?

Informed about guidance on the use of systemic o primjeni sistemskih antibiotika u endodonciji?

Guidelines followed for prescribing regiments among suspectable patient $\bullet$ Čije smjernice pratite u primjeni antibiotika $\mathrm{u}$ endodonciji? antibiotics in endodontics $\bullet$ Informirani ste o smjernicama

\begin{tabular}{|c|c|c|c|}
\hline \multirow[b]{2}{*}{$\mathrm{No} \bullet \mathrm{Ne}$} & \multirow[b]{2}{*}{$334(50.8)$} & \multirow[b]{2}{*}{$11.5 \pm 2.4$} & \multirow[b]{3}{*}{0.074} \\
\hline & & & \\
\hline Yes $\bullet \mathrm{Da}$ & $323(49.2)$ & $11.9 \pm 2.6$ & \\
\hline $\mathrm{No} \bullet \mathrm{Ne}$ & $114(21.9)$ & $11.1 \pm 2.3$ & \multirow{2}{*}{0.006} \\
\hline Yes $\bullet \mathrm{Da}$ & $513(78.1)$ & $11.8 \pm 2.6$ & \\
\hline $\begin{array}{l}\text { Croatian Endodontic Society } \\
\text { Hrvatskoga endodontskog društva }\end{array}$ & $367(55.9)$ & $11.5 \pm 2.5^{\mathrm{a}, \mathrm{b}}$ & \multirow{5}{*}{$\leq 0.001$} \\
\hline $\begin{array}{l}\text { European Society of Endodontology } \bullet \\
\text { Europskoga endodontološkog društva }\end{array}$ & $74(11.3)$ & $12.6 \pm 2.6^{\mathrm{a}, \mathrm{c}}$ & \\
\hline $\begin{array}{l}\text { British Society of Cardiology } \bullet \\
\text { Britanskoga kardiološkog društva }\end{array}$ & $13(2.0)$ & $12.5 \pm 2.8$ & \\
\hline $\begin{array}{l}\text { American Cardiac Association • } \\
\text { Američkoga kardiološkog društva }\end{array}$ & $49(7.5)$ & $12.7 \pm 2.5^{\mathrm{b}, \mathrm{d}}$ & \\
\hline Others $\bullet$ Ostalo & $154(23.4)$ & $11.1 \pm 2.3^{\mathrm{c,d}}$ & \\
\hline Very good $\bullet$ Veoma dobro & $33(5.0)$ & $12.0 \pm 2.8$ & \multirow{4}{*}{0.966} \\
\hline Good $\bullet$ Dobro & $341(49.1)$ & $11.7 \pm 2.6$ & \\
\hline Fair $\bullet$ Nedovoljno & $271(41.2)$ & $11.6 \pm 2.3$ & \\
\hline Poor $・$ Loše & $12(1.8)$ & $12.2 \pm 2.7$ & \\
\hline $\mathrm{No} \bullet \mathrm{Ne}$ & $573(87.2))$ & $11.7 \pm 2.5$ & \multirow[b]{2}{*}{0.168} \\
\hline Yes $\bullet \mathrm{Da}$ & $84(12.7)$ & $11.3 \pm 2.5$ & \\
\hline $\mathrm{No} \bullet \mathrm{Ne}$ & $530(80.7)$ & $11.7 \pm 2.5$ & \multirow[b]{2}{*}{0.873} \\
\hline Yes $\bullet \mathrm{Da}$ & $127(19.3)$ & $11.7 \pm 2.4$ & \\
\hline $\mathrm{No} \bullet \mathrm{Ne}$ & $447(68.0)$ & $11.6 \pm 2.5$ & \multirow{2}{*}{0.108} \\
\hline Yes $\bullet \mathrm{Da}$ & $210(32.0)$ & $11.9 \pm 2.6$ & \\
\hline None $\bullet$ Ni jedanput & $126(19.2)$ & $11.7 \pm 2.5$ & \multirow{3}{*}{0.627} \\
\hline Once $\bullet$ Jedanput & $190(28.9)$ & $11.5 \pm 2.3$ & \\
\hline More than once $\bullet$ Više od jedanput & $341(51.9)$ & $11.7 \pm 2.7$ & \\
\hline Always • Uvijek & $3(0.5)$ & $11.9 \pm 2.8$ & \multirow{5}{*}{0.940} \\
\hline Very frequently $\bullet$ Veoma često & $22(3.3)$ & $11.6 \pm 2.0$ & \\
\hline Occasionally $\bullet$ Katkad & $228(34.7)$ & $11.6 \pm 2.4$ & \\
\hline Rarely • Rijetko & $286(43.5)$ & $11.7 \pm 2.6$ & \\
\hline Very rarely $\bullet$ Veoma rijetko & $118(18.0)$ & $11.5 \pm 2.7$ & \\
\hline $\begin{array}{l}\text { Antibiotic - drug interactions } \\
\text { Interakcije antibiotika i drugih lijekova }\end{array}$ & $260(39.6)$ & $11.9 \pm 2.6$ & \multirow{5}{*}{0.519} \\
\hline $\begin{array}{l}\text { Types of antibiotics recommended } \\
\text { dosages and duration } \bullet \text { Vrste } \\
\text { antibiotika, preporučene doze i trajanje } \\
\text { terapije }\end{array}$ & $35(5.3)$ & $11.4 \pm 2.5$ & \\
\hline $\begin{array}{l}\text { Prescription of antibiotics to children, } \\
\text { pregnant and lactating women } \\
\text { - Propisivanje antibiotika djeci, } \\
\text { trudnicama i dojiljama }\end{array}$ & $212(32.3)$ & $11.6 \pm 2.5$ & \\
\hline $\begin{array}{l}\text { Indications for antibiotics during } \\
\text { endodontic therapies } \bullet \text { Indikacije za } \\
\text { primjenu antibiotika u endodonciji }\end{array}$ & $74(11.3)$ & $11.4 \pm 2.3$ & \\
\hline Other $\bullet$ Ostalo & 76 (11.6) & $11.3 \pm 2.5$ & \\
\hline
\end{tabular}

How would you rate your knowledge regarding the usage of antibiotics in endodontics? $\bullet$ Kako biste ocijenili svoje znanje o primjeni antibiotika u endodonciji?

After root canal therapy, have you ever prescribed antibiotics for postoperative pain? $\bullet$ Nakon endodontske terapije, jeste li ikada propisali antibiotike za postoperativnu bol?

Have you ever prescribed antibiotics in endodontics to achieve a placebo effect? $\bullet$ Jeste li ikada u endodonciji propisivali antibiotike kako biste postigli placebo učinak? Do you prescribe a leading (double) dose of antibiotics for an endodontic infection? • Propisujete li početnu (dvostruku) dozu antibiotika za endodontsku infekciju? Number of prescribed systemic antibiotic for prophylaxis during last year $\bullet$ Broj propisanih sistemskih antibiotika za profilaksu tijekom prošle godine?

How often do you doubt justification when prescribing antibiotics in case of endodontic infections? $\bullet$ Koliko često sumnjate u opravdanost propisivanja antibiotika u slučaju endodontskih infekcija?

What are your "knowledge gaps” regarding the usage of antibiotics in endodontics? $\bullet$ Koje su Vaše „praznine u znanju" o primjeni antibiotika u endodonciji?

\section{No $\bullet$ N}

Croatian Endodontic Society •

Hrvatskoga endodontskog društva

European Society of Endodontology

British Society of Cardiology •

Britanskoga kardioloskog drustva

Američkoga kardiološkog društva

Very good $\bullet$ Veoma dobro

Good $\bullet$ Dobro 


\section{Discussion}

This cross-sectional questionnaires-based study found insufficient knowledge regarding antibiotic prescription in endodontics among Croatian dentists. Although most participants reported being familiar with some of the available guidelines on the use of antibiotics, the overall score was only $50 \%$ of the overall maximum score. Similar results suggesting insufficient knowledge, practice, and attitudes regarding antibiotics use were reported among dentists and dental students in Italy, Turkey, Saudi Arabia, and Iran (22-26).

Interestingly, the youngest respondents with the least clinical experience (one to five years) demonstrated the highest level of knowledge, which is in line with the recommendations from the European Society of Endodontology (17). This may be explained by the fact that they most recently completed their formal university education. Also, endodontics specialists showed better knowledge than general practitioners and specialists in other fields of dentistry, which can be explained by their specific training in the field of interest.

Although the ESE guidelines recommended Penicillin V and Amoxicillin as the first-line antibiotics for the treatment of endodontic infections in cases of no allergy to penicillin, only $2 \%$ and $17.2 \%$ of the dentists answered correctly (17, 18). Amoxicillin with clavulanic acid was reported to be the most frequently prescribed antibiotic. Similar reports were observed in studies involving dentists from Saudi Arabia and Turkey. However, they are also in line with the latest studies conducted in Croatia $(15,23,24,27,28,29)$. Likewise, Lithuanian, UK, and Australian dentists considered Amoxicillin the most preferred antibiotic during endodontic treatment (3032). However, in a study involving dentists from Sweden, the most frequently prescribed antibiotic was penicillin VK (33).

According to the ESE guidelines, in case of penicillin allergy, possible alternatives include Clindamycin, Clarithromycin, or Azithromycin (17). In this study, Clindamycin was most often $(83.3 \%)$ reported alternative to Penicillin. Clarithromycin or Azithromycin were selected as substitutes to Penicillin very rarely, with the frequency of answers being $0.6 \%$, and $1.7 \%$, respectively. Clindamycin was also the antibiotic of choice in cases of penicillin allergies among dentists in Saudi Arabia, Serbia, Turkey, and Spain $(23,26,34,35)$.

If clinical signs and symptoms do not improve in 2-3 days of taking the first-line antibiotics, it is recommended to use a supplementary one $(33,36)$. In Europe, Metronidazole is the antibiotic of choice when penicillin alone is not effective, because of its effectiveness against anaerobic bacteria. Therefore, it is usually combined with Penicillin, and more than half of the dentists in this study agreed with this recommendation (36).

Furthermore, because most oral infections have a rapid onset, it is necessary to establish minimum inhibitory antibiotic concentration fast (36). Thus, a loading dose (first double dose) is recommended $(17,18)$. This recommendation of the European Endodontic Society was known to around onethird of the dentist from this study.

Acute oral infections are most often resolved within 3-7 days (37). In most cases, antibiotics should be prescribed

\section{Rasprava}

Ovom presječnom studijom na temelju upitnika ustanovljeno je da doktori dentalne medicine u Republici Hrvatskoj nemaju dovoljno znanja o propisivanju antibiotika u endodonciji. Unatoč tomu što je većina njih izjavila da je obaviještena o nekima od dostupnih smjernica o upotrebi antibiotika, ukupni rezultat bio je samo $50 \%$ maksimalnog rezultata.

Slični rezultati koji sugeriraju nedovoljno znanja, prakse i stajališta u vezi s upotrebom antibiotika zabilježeni su među doktorima dentalne medicine i studentima u Italiji, Turskoj, Saudijskoj Arabiji i Iranu (22 - 26).

Zanimljivo je da su najmlađi ispitanici s najmanje kliničkog iskustva (od jedne do pet godina) pokazali najvišu razinu znanja koja je bila u skladu s preporukama Europskoga endodontskoga društva (17). To se može objasniti činjenicom da su nedavno završili formalno visoko obrazovanje. Specijalisti endodoncije također su pokazali bolje znanje od općih doktora dentalne medicine i specijalista iz drugih područja dentalne medicine, što se može objasniti njihovom specifičnom edukacijom iz područja od interesa za ovo istraživanje.

Iako smjernice Europskoga endodontskoga društva preporučuju penicilin $\mathrm{V}$ i amoksicilin kao antibiotike prve linije za liječenje endodontskih infekcija u slučajevima bez alergije na penicilin, samo $2 \%$ doktora dentalne medicine dalo je točan odgovor za penicilin V i 17,2 \% za amoksicilin $(17,18)$. Amoksicilin s klavulanskom kiselinom naveden je kao najčešće propisivani antibiotik. Slična izvješća su i u studijama u kojima su sudjelovali doktori dentalne medicine iz Saudijske Arabije i Turske, i u skladu su s najnovijim studijama provedenima u Hrvatskoj (15, 23, 24, 27, 28, 29). Litavski, britanski i australski doktori dentalne medicine također su ocijenili amoksicilin najpoželjnijim antibiotikom tijekom endodontskoga liječenja $(30-32)$. No u studiji u kojoj su sudjelovali doktori dentalne medicine iz Švedske najčešće propisivani antibiotik bio je penicilin VK (33).

Prema smjernicama Europskoga endodontskoga društva, u slučaju alergije na penicilin, moguće zamjene su klindamicin, klaritromicin ili azitromicin (17). U ovoj studiji je klindamicin bio najčešće $(83,3 \%)$ navedena alternativa za penicilin. Klaritromicin ili azitromicin vrlo su rijetko odabrani kao zamjena za penicilin - učestalost odgovora bila je 0,6 \% za klaritromicin, odnosno 1,7 \% za azitromicin. Klindamicin je također bio antibiotik izbora u slučaju alergija na penicilin među doktorima dentalne medicine u Saudijskoj Arabiji, Srbiji, Turskoj i Španjolskoj (23, 26, 34, 35).

U slučaju kada se klinički znakovi i simptomi ne poboljšaju nakon dva do tri dana uzimanja antibiotika prve linije, preporučuje se primjena dopunskog antibiotika $(33,36)$. U Europi je, uz penicilin, metronidazol antibiotik izbora zbog njegove učinkovitosti protiv anaerobnih bakterija. Zato se obično kombinira s penicilinom, te se više od polovine doktora dentalne medicine u ovoj studiji složilo $s$ tom preporukom (36).

Nadalje, budući da većina oralnih infekcija brzo počinje, potrebno je što prije uspostaviti minimalnu inhibitornu koncentraciju antibiotika (36). Zato se preporučuje udarna doza (prva dvostruka doza) $(17,18)$. Ta je preporuka Europskoga 
only for the period in which improvement of symptoms is achieved and should not be continued 1-2 days after withdrawal of clinical signs of infection (38). Also, a shorter use of antibiotics lowers the risk of the development of resistant microorganisms (36). Almost half of the responders in this study answered that a full, long course of antibiotics should be administrated, with about one-third answering that the duration of the therapy should be three to seven days. The results from similar studies conducted in Brazil, Saudi Arabia, and Spain reported the average time of antibiotic usage being seven days, which is considered to be unnecessarily long $(34,39,40)$.

Regarding the indications for antibiotic prescribing, most participants (84\%) responded that the indication for antibiotic therapy was an acute apical abscess with the existence of systemic signs of infection. A smaller proportion of participants (14\%) reported that an acute apical abscess without systemic symptoms required antibiotic therapy, and only $2 \%$ of participants reported one of the remaining responses (symptomatic reversible pulpitis, pulp necrosis, symptomatic apical periodontitis, and chronic apical periodontitis with sinus tract) as an indication for antibiotic administration. In such situations, the use of antibiotics is considered futile, because due to the lack of pulp circulation, antibiotics cannot reach the endodontic space and eliminate bacteria (7). These results are comparable to the results of Alonso et al. (40) where $83.3 \%$ of respondents answered that acute apical abscess is an indication for antibiotic therapy. Croatian dentists showed better knowledge compared to studies of Alatas et al. (39) and Whitten et al. (33) where only $31.2 \%$, and almost 50\%, of respondents, respectively, answered that antibiotics are indicated in acute apical periodontitis with systematic involvement. Although, in relation to the before-mentioned studies, a relatively low percentage of dentists $(16 \%)$ in this study answered that antibiotics are indicated in cases when treatment could be reduced with non-surgical root canal therapy with analgesics, if necessary, there is still space for improvements in better understanding of antibiotics use $(33,39)$.

Nevertheless, antibiotics should be administered in immuno- compromised patients to avoid complications associated with endodontic-associated bacteremia. Particularly vulnerable groups of patients are patients with localized congenital heart defects, patients with impaired immunologic function, patients with prosthetic joint replacement within three months of surgery, patients whose jawbones are exposed to high-dose irradiation, and patients receiving intravenous bisphosphonate treatment $(7,41,42)$. This study has shown a high percentage of dentists having sufficient knowledge regarding antibiotic prophylaxis administration. A small number of participants considered antibiotic prophylaxis appropriate in patients with non-cyanotic heart defects, for patients with liver disease or high blood pressure. Data on the use of antibiotic prophylaxis from other studies are heterogeneous but they show that clinicians are not always sure whether antibiotic prophylaxis is needed; therefore they use it defensively. On the other hand, certain diagnoses that are clear indications of the need for prophylaxis remain unrecognized, thus putting the patient an increased risk of develop- endodontskoga društva bila poznata otprilike jednoj trećini doktora dentalne medicine iz ove studije.

Akutne oralne infekcije najčešće se povlače za tri do sedam dana (37). U većini slučajeva antibiotike je potrebno propisivati samo u razdoblju u kojemu se očekuje poboljšanje simptoma i trebalo bi ih nastaviti koristiti dan do dva dana nakon povlačenja kliničkih znakova infekcije (38). Kraća primjena antibiotika također smanjuje rizik od pojave rezistentnih mikroorganizama (36). Gotovo polovina ispitanika u ovoj studiji odgovorila je da treba dati punu dugu kuru antibiotika, a otprilike jedna trećina istaknula je da bi terapija trebala trajati od tri do sedam dana. Rezultati sličnih studija provedenih u Brazilu, Saudijskoj Arabiji i Španjolskoj pokazuju da je prosječna upotreba antibiotika sedam dana, što se smatra nepotrebno dugim razdobljem $(34,39,40)$.

Kad je riječ o indikacijama za propisivanje antibiotika, većina ispitanika $(84 \%)$ odgovorila je da je indikacija za antibiotičku terapiju akutni apikalni apsces sa sistemskim znakovima infekcije. Manji udio (14\%) naveo je da akutni apikalni apsces bez sistemskih simptoma zahtijeva antibiotičku terapiju, a samo $2 \%$ odabralo je jedan od preostalih odgovora kao indikaciju za primjenu antibiotika (simptomatski reverzibilni pulpitis, nekroza pulpe, simptomatski apikalni parodontitis i kronični apikalni parodontitis sa sinusnog trakta). U takvim situacijama primjena antibiotika smatra se beskorisnom zato što zbog nedostatka cirkulacije u pulpi antibiotici ne mogu dospjeti u endodontski prostor i eliminirati bakterije (7). Ti se rezultati mogu usporediti s onima Alonsa i suradnika (40) u kojima je 83,3\% ispitanika odgovorilo da je akutni apikalni apsces indikacija za antibiotičku terapiju. Hrvatski doktori dentalne medicine pokazali su bolje znanje u usporedbi s istraživanjem Alatasa i suradnika (39) i Whittena i suradnika (33) u kojima je samo $31,2 \%$, odnosno gotovo $50 \%$ ispitanika odgovorilo da su antibiotici indicirani u liječenju akutnoga apikalnoga parodontitisa sa sustavnim zahvaćanjem. Iako u usporedbi s prije spomenutim studijama razmjerno nizak postotak doktora dentalne medicine $(16 \%)$ u ovoj studiji odgovorio je da bi primijenio antibiotičku terapiju u slučaju da zahvat zahtijeva isključivo nekirurški pristup uz eventualnu primjenu analgetika. Iz toga se može zaključiti da ima prostora za poboljšanje znanja i razumijevanja kad je riječ o primjeni antibiotika u endodonciji $(33,39)$.

U svakom slučaju, imunokompromitiranim pacijentima treba davati antibiotike da se izbjegnu komplikacije povezane $s$ endodontskom bakterijemijom. Posebno ranjive skupine pacijenata su oni $s$ lokaliziranim prirođenim srčanim manama, s oslabljenom imunošću, s protetičkim nadomjestkom zgloba unutar tri mjeseca poslije operacije, zatim oni čije su čeljusne kosti izložene visokim dozama zračenja te ako se liječe intravenskim bisfosfonatima $(7,41,42)$. Ova studija pokazala je da visok postotak doktora dentalne medicine ima dovoljno znanja o primjeni antibiotičke profilakse. Manjina je smatrala takvu profilaksu primjerenom za pacijente s necijanotičnim srčanim manama te za one s bolešću jetre ili visokim krvnim tlakom. Podatci o primjeni antibiotičke profilakse iz drugih studija su heterogeni, ali pokazuju da kliničari nisu uvijek sigurni u njezinu nužnost te se njome koriste defenzivno, a s druge strane određene dijagnoze, koje su jasni 
ing bacteremia $(43,44)$. Moreover, almost all dentists in our study considered endodontic surgery an indication for the use of prophylactic antibiotics.

The answers related to the retreatment procedure mostly depended on the symptomatology and the presence of signs of apical periodontitis on $\mathrm{X}$-rays. Thus, the largest number of dentists answered that prophylaxis is necessary for the retreatment of root canals with apical periodontitis, while only $2.7 \%$ of dentists considered prophylaxis in the procedure of retreatment of an asymptomatic tooth without signs of apical periodontitis on X-ray.

Certain techniques of local anesthesia in dentistry, such as intraligamentary injection, require antibiotic prophylaxis in patients with the risk of developing infectious endocarditis (17). However, in this study, almost one-third of dentists reported the usage of prophylaxis before the application of intraligamentary anesthesia. Findings from the study by Mansour et al. (43) were even more disturbing bacause only $4,6 \%$ of participants reported that prophylaxis is needed before the intraligamentary anesthesia.

On the other hand, using antibiotic prophylaxis before procedures for which it is not indicated, as reported by some of the dentists in this study, may only contribute to the development of resistant strains of microorganisms. Croatian dentists have shown satisfactory knowledge about the usage of antibiotic prophylaxis when compared with prescription patterns seen in the USA, where $80,9 \%$ of antibiotic prophylaxis prescriptions were found to be unnecessary and in contrast to the available guidelines (45).

In addition to all the above-mentioned issues concerning antibiotic prescribing, there is also an issue of prescribing antibiotic therapy to achieve a placebo effect. Bjelovucic et al. (27) reported that lack of time to perform adequate treatment often leads to over-prescription of antibiotics. In this study, one-fifth of participants answered that they had prescribed antibiotics one or more times, but it was only to achieve the placebo effect. These findings suggest that many practitioners still give in to the patients' pressure rather than to the available guidelines. These are, however, issues caused by multifactorial origins, and might only be well understood through a qualitative approach. Also, almost $40 \%$ of dentists considered that they lacked knowledge in the field of drug interactions with antibiotics, with one-third of them feeling insecure when prescribing antibiotics to children or pregnant and lactating women.

Bearing on mind the fact that an inappropriate use of antibiotics and lack of knowledge on their rational use can lead to antibiotic resistance, dental health professionals need to reduce antibiotic prescriptions by following the available upto-date guidelines. According to a recent systematic review, it is necessary to improve worldwide prescribing habits of antibiotics in the treatment of endodontic infections (33).

Since this study was conducted using an online questionnaire, the limitations are common to other questionnairebased studies, including the problem of the low response rate, the risk of socially desirable responses, and the consistency of responses. These findings thus encourage more rigorous methods in order to stimulate higher participation in future pokazatelji da je potrebna profilaksa, ostaju neprepoznati te tako dovode pacijenta u rizik od razvoja bakterijemije (43, 44). Štoviše, gotovo svi sudionici u našoj studiji smatrali su endodontsku kirurgiju indikacijom za primjenu profilaktičnih antibiotika.

Odgovori vezani uz postupak ponovnoga liječenja uglavnom su ovisili o simptomatologiji i znakovima apikalnoga parodontitisa na rendgenskim snimkama. Tako je najviše ispitanika odgovorilo da je profilaksa prijeko potrebna u slučaju ponovnog liječenja korijenskih kanala s apikalnim parodontitisom, a samo $2,7 \%$ stomatologa razmatralo je profilaksu u postupku ponovnog liječenja asimptomatskoga zuba bez znakova apikalnoga parodontitisa na rendgenu.

Određene tehnike u primjeni lokalne anestezije, poput intraligamentarne, zahtijevaju antibiotičku profilaksu za pacijente kod kojih postoji rizik od bakterijskog endokarditisa (17). No u ovoj studiji samo je jedna trećina doktora dentalne medicine navela korištenje profilakse prije primjene intraligamentarne anestezije. Još više zabrinjavaju rezultati u studiji Mansoura i suradnika (43) koji ističu da je samo 4,6 \% ispitanika izjavilo da je profilaksa potrebna prije intraligamentarne anestezije.

$S$ druge pak strane, korištenje antibiotičke profilakse prije zahvata za koje nije indicirana, kako navode neki od doktora u ovoj studiji, može samo pridonijeti pojavi rezistentnih sojeva mikroorganizama. Hrvatski doktori dentalne medicine pokazali su zadovoljavajuće znanje o primjeni antibiotičke profilakse u usporedbi s propisivanjem antibiotika u SADu gdje se procjenjuje da je 80,9 \% recepata za antibiotičku profilaksu nepotrebno i u suprotnosti s dostupnim smjernicama (45).

Uza sve navedene probleme u propisivanju antibiotika, postavlja se i pitanje propisivanja antibiotičke terapije za postizanje placebo učinka. Bjelovučić i suradnici (27) izvijestili su da nedostatak vremena za adekvatno liječenje često rezultira pretjeranim propisivanjem antibiotika. $U$ ovoj studiji jedna je petina sudionika odgovorila da su antibiotike propisali jedanput ili više puta, ali samo da bi postigli placebo učinak. Ti nalazi pokazuju da mnogi liječnici i dalje popuštaju pacijentima i ne djeluju u skladu s dostupnim smjernicama. No to su pitanja potaknuta različitim čimbenicima i mogu se dobro razumjeti samo na temelju kvalitativnoga istraživačkog pristupa. Gotovo $40 \%$ doktora dentalne medicine također smatra da im nedostaje znanje iz područja interakcije lijekova $s$ antibioticima, pri čemu se jedna trećina osjeća nesigurno pri propisivanju antibiotika djeci, trudnicama i dojiljama.

S obzirom na to da neodgovarajuća uporaba antibiotika i nedostatak znanja o njihovoj racionalnoj promjeni mogu završiti rezistencijom na taj lijek, stručnjaci iz područja dentalne medicine, slijedeći dostupne aktualne smjernice, moraju smanjiti propisivanje antibiotika. Prema nedavnom sustavnom pregled potrebno je poboljšati svjetske navike u propisivanju antibiotika tijekom liječenja endodontskih infekcija (33).

Budući da je ova studija provedena na temelju internetskog upitnika, ograničenja su zajednička ostalim tako provedenim studijama, uključujući i problem niske stope odgovora, rizik u društveno poželjnim odgovorima i dosljednost 
studies, thus allowing better representativeness and generalizability of the results. That in turn, should guide future training on antibiotic use in everyday clinical settings, with specifically tailored regular and up-to-date reports of the best available evidence on antibiotic prescribing to meet the needs of practicing dentists.

\section{Conclusions}

Croatian dentists' level of knowledge regarding antibiotic prescription practice in endodontic is not entirely satisfactory. Younger dentists showed better knowledge; likewise those with specialist training, as well as those familiar with guidelines on the use of systemic antibiotics in endodontics. Specifically tailored educational interventions for dentists, including campaigns and lectures on the appropriate use of antibiotics and prevention of antibiotic resistance, are needed.

\section{Funding Information}

No funding was received for this article.

\section{Conflict of interest}

The authors declare no conflict of interest related to this study.

Author Contributions: M.S.M., I.S., and T.P.P. - have contributed substantially to the concept and design of the study; N.C., T.P.P., and M.B. - have significantly contributed to the acquisition of data; A.T. has analyzed and interpreted the data; M.S.M., I.S., A.T., I.B., and T.P.P. have performed the literature search and wrote the manuscript. All authors have revised the manuscript critically for important intellectual content, and all authors have read and agreed to the published version of the manuscript. odgovora. Zato ovi nalazi potiču na rigoroznije metode za poticanje većeg sudjelovanja u budućim studijama kako bi se omogućila bolja reprezentativnost i poopćenost rezultata. To bi zauzvrat trebalo usmjeriti buduću izobrazbu o upotrebi antibiotika u svakodnevnom kliničkom okružju, s posebno prilagođenim, redovito ažuriranim izvješćima o najboljim dostupnim dokazima o propisivanju antibiotika koji bi odgovarali potrebama doktora dentalne medicine u svakodnevnoj praksi.

\section{Zaključak}

Razina znanja hrvatskih doktora dentalne medicine o propisivanju antibiotika u endodonciji nije u cijelosti zadovoljavajuća. Bolje znanje pokazali su mlađi stomatolozi, specijalisti i oni koji su informirani o smjernicama o primjeni sistemskih antibiotika u endodonciji. To pokazuje da su potrebne posebno prilagođene edukativne intervencije za doktore dentalne medicine, uključujući kampanje i predavanja o pravilnoj primjeni antibiotika i prevenciji rezistencije na te lijekove.

\section{Financiranje studije}

Autori ni od koga nisu dobili financijska sredstva za ovu studiju.

\section{Sukob interesa}

Autori nisu bili u sukobu interesa.

Doprinos autora: M. S. M., I. S. i T. P. P. - znatno su pridonijele koncepciji i osmišljavanju ustroja studije; N. C., T. P. P. i M. B. - znatno su pridonijele prikupljanju podataka; M. S. M., I. S., A. T., I. B. i T. P. P. - obavile su analizu literature i sudjelovale u pisanju rada. Svi autori kritički su pregledali rad u odnosu na važan intelektualni sadržaj i svi su pročitali i odobrili verziju poslanu za objavljivanje.

\section{Sažetak}

Ciljevi: Procijeniti razinu znanja i iskustva stomatologa o primjeni antibiotika u endodonciji koristeći se kao referencijom konsenzusom Europskoga endodontološkoga društva. Materijal i metode: Ovo presječno istraživanje provedeno je na temelju elektroničkoga upitnika sastavljenoga od 23 pitanja, uključujući demografske i profesionalne značajke doktora dentalne medicine, njihova stajališta i iskustva u vezi s korištenjem antibiotika u endodonciji. Podatci su analizirani Mann-Whitneyjevim testom ili Kruskal-Wallisovim jednosmjernim ANOVA testom $-\alpha=5 \%$. Rezultati: Ukupna prosječna vrijednost znanja doktora dentalne medicine iznosila je 11,7 $\pm 2,5$ bodova, od najviše mogućih 23 . Čimbenici povezani s višim znanjem bili su dob $(P \leq 0,001)$, kliničko iskustvo $(P \leq 0,001)$, specijalističko usavršavanje $(P=0,008)$ te poštovanje smjernica o primjeni sistemskih antibiotika u endodonciji ( $P$ $=0,006)$. Doktori dentalne medicine koji su specijalizirali endodonciju $(16,1 \pm 2,2)$ postigli su višu razinu znanja. Zaključak: Znanje o primjeni antibiotika u endodonciji među doktorima dentalne medicine u Republici Hrvatskoj je nedostatno. Potrebna je stalna edukacija o upotrebi antibiotika među populacijom općih doktora dentalne medicine.
Zaprimljen: 22. kolovoza 2021 Prihvaćen: 10. studenog 2021.

Adresa za dopisivanje Antonija Tadin

Sveučilište u Splitu

Medicinski fakultet Studij dentalne medicine

Zavod za restaurativnu dentalnu medicinu i endodonciju

Šoltanska 2, 21000 Split, Hrvatska, telefon: +38598609191

atadin@mefst.hr,dr.antonija.tadin@ gmail.com

ORCID ID: 0000-0002-5365-9816

MeSH pojmovi: stomatolozi; endodoncija; antibakterijska sredstva; zdravstveno znanje stavovi i praksa Autorske ključne riječi: antibiotici; doktori dentalne medicine; znanje; upitnik 


\section{References}

1. Siqueira JF Jr, Rocas IN. Present status and future directions in endodontic microbiology. Endodontic Topics. 2014;30:3-22.

2. Galler KM, Krastl G, Simon S, Van Gorp G, Meschi N, Vahedi B, et al. European Society of Endodontology position statement: Revitalization procedures. Int Endod J. 2016 Aug;49(8):717-23.

3. Cope AL, Chestnutt IG. Inappropriate prescribing of antibiotics in primary dental care: reasons and resolutions. Prim Dent J. 2014 Nov;3(4):33-7.

4. Fouad AF, Rivera EM, Walton RE. Penicillin as a supplement in resolving the localized acute apical abscess. Oral Surg Oral Med Oral Pathol Oral Radiol Endod. 1996 May;81(5):590-5.

5. Henry M, Reader A, Beck M. Effect of penicillin on postoperative endodontic pain and swelling in symptomatic necrotic teeth. J Endod. 2001 Feb;27(2):117-23.

6. Keenan JV, Farman AG, Fedorowicz Z, Newton JT. A Cochrane systematic review finds no evidence to support the use of antibiotics for pain relief in irreversible pulpitis. J Endod. 2006 Feb;32(2):87-92.

7. Segura-Egea JJ, Gould K, Sen BH, Jonasson P, Cotti E, Mazzoni A, et al. Antibiotics in Endodontics: a review. Int Endod J. 2017 Dec;50(12):1169-1184.

8. Parahitiyawa NB, Jin LJ, Leung WK, Yam WC, Samaranayake LP. Microbiology of odontogenic bacteremia: beyond endocarditis. Clin Microbiol Rev. 2009 Jan;22(1):46-64, Table of Contents.

9. Agnihotry A, Fedorowicz Z, van Zuuren EJ, Farman AG, Al-Langawi $\mathrm{JH}$. Antibiotic use for irreversible pulpitis. Cochrane Database Syst Rev. 2016 Feb 17;2:CD004969.

10. Loffler C, Bohmer F. The effect of interventions aiming to optimise the prescription of antibiotics in dental care-A systematic review. PLoS One. 2017 Nov 14;12(11):e0188061.

11. Antibiotic Resistance Threats in the United States, 2019 [Internet]. Atlanta, GA: U.S. Department of Health and Human Services, CDC; 2019 [cited 2021 May 6]. Available from: https://www. cdc.gov/drugresistance/pdf/threats-report/2019-ar-threats-report-508.pdf

12. Kaptan RF, Haznedaroglu F, Basturk FB, Kayahan MB. Treatment approaches and antibiotic use for emergency dental treatment in Turkey. Ther Clin Risk Manag. 2013;9:443-9.

13. Costelloe C, Metcalfe C, Lovering A, Mant D, Hay AD. Effect of antibiotic prescribing in primary care on antimicrobial resistance in individual patients: systematic review and meta-analysis. BMJ. 2010 May 18;340:c2096.

14. Gonzales R, Malone DC, Maselli JH, Sande MA. Excessive antibiotic use for acute respiratory infections in the United States. Clin Infect Dis. 2001 Sep 15;33(6):757-62.

15. Sutej I, Lepur D, Bozic D, Pernaric K. Medication Prescribing Practices in Croatian Dental Offices and Their Contribution to National Consumption. Int Dent J. 2021 Feb 26;S0020-6539(21)00004-6.

16. Sutej I, Peros K, Trkulja V, Rudez I, Baric D, Alajbeg I, et al. The epidemiological and clinical features of odontogenic infective endocarditis. Eur J Clin Microbiol Infect Dis. 2020 Apr;39(4):637-645.

17. Segura-Egea JJ, Gould K, Sen BH, Jonasson P, Cotti E, Mazzoni A, et al. European Society of Endodontology position statement: the use of antibiotics in endodontics. Int Endod J. 2018 Jan;51(1):2025.

18. Palmer NO, Martin MV, Pealing R, Ireland RS, Roy K, Smith A, et al. Antibiotic prescribing knowledge of National Health Service general dental practitioners in England and Scotland. J Antimicrob Chemother. 2001 Feb;47(2):233-7.

19. Bloom BS. Learning for mastery. Instruction and curriculum. Regional education laboratory for the Carolinas and Virginia. Evaluation comment. 1968;2(2):1-12.

20. STROBE statement--checklist of items that should be included in reports of observational studies (STROBE initiative). Int J Public Health. 2008;53(1):3-4.

21. Hrvatski zdravstveno-statistički ljetopis za 2019. godinu [Internet]. Zagreb: Hrvatski zavod za javno zdravstvo, 2019 [cited 2021 May 6]. Available from: https://www.hzjz.hr/hrvatski-zdravstveno-statisticki-ljetopis/hrvatski-zdravstveno-statisticki-ljetopisza-2019/.

22. Salvadori M, Audino E, Venturi G, Garo ML, Salgarello S. Antibiotic prescribing for endodontic infections: a survey of dental students in Italy. Int Endod J. 2019 Sep;52(9):1388-1396.

23. Deniz-Sungur D, Aksel H, Karaismailoglu E, Sayin TC. The prescribing of antibiotics for endodontic infections by dentists in Turkey: a comprehensive survey. Int Endod J. 2020 Dec;53(12):1715-1727.
24. Iqbal A. The Attitudes of Dentists Towards the Prescription of Antibiotics During Endodontic Treatment in North of Saudi Arabia. J Clin Diagn Res. 2015 May;9(5):ZC82-4.

25. Nabavizadeh MR, Sahebi S, Nadian I. Antibiotic prescription for endodontic treatment: general dentist knowledge + practice in shiraz. Iran Endod J. Spring 2011;6(2):54-9.

26. AlRahabi MK, Abuong ZA. Antibiotic abuse during endodontic treatment in private dental centers. Saudi Med J. 2017 Aug;38(8):852-856

27. Bjelovucic R, Par M, Rubcic D, Marovic D, Prskalo K, Tarle Z. Antibiotic prescription in emergency dental service in Zagreb, Croatia - a retrospective cohort study. Int Dent J. 2019 Aug;69(4):273280.

28. Peric M, Perkovic I, Romic M, Simeon P, Matijevic J, Mehicic GP, et al. The Pattern of Antibiotic Prescribing by Dental Practitioners in Zagreb, Croatia. Cent Eur J Public Health. 2015;23(2):107-13.

29. Sović J, Šegović S, Tomasić I, Pavelić B, Šutej I, Anić I. Antibiotic Administration Along with Endodontic Therapy in the Republic of Croatia: a Pilot Study. Acta Stomatol Croat. 2020 Sep;54(3):314321.

30. Palmer NA, Pealing R, Ireland RS, Martin MV. A study of therapeutic antibiotic prescribing in National Health Service general dental practice in England. Br Dent J. 2000 May 27;188(10):554-8.

31. Jaunay T, Sambrook P, Goss A. Antibiotic prescribing practices by South Australian general dental practitioners. Aust Dent J. 2000 Sep;45(3):179-86; quiz 214

32. Skucaite N, Peciuliene V, Maneliene R, Maciulskiene V. Antibiotic prescription for the treatment of endodontic pathology: a survey among Lithuanian dentists. Medicina (Kaunas). 2010;46(12):80613.

33. Farzeen T, Hafiza J A, Yousra M M, et al. Antibiotic Prescription Habits of Swedish Dentists. Pak Oral Dent J. 2012 32: 460-463.

34. Drobac M, Otasevic K, Ramic B, Cvjeticanin M, Stojanac I, Petrovic L. Antibiotic Prescribing Practices in Endodontic Infections: A Survey of Dentists in Serbia. Antibiotics (Basel). 2021 Jan 12;10(1):67.

35. Segura-Egea JJ, Martin-Gonzalez J, Jimenez-Sanchez MDC, Crespo-Gallardo I, Sauco-Marquez JJ, Velasco-Ortega E. Worldwide pattern of antibiotic prescription in endodontic infections. Int Dent J. 2017 Aug;67(4):197-205.

36. Bolfoni MR, Pappen FG, Pereira-Cenci T, Jacinto RC. Antibiotic prescription for endodontic infections: a survey of Brazilian Endodontists. Int Endod J. 2018 Feb;51(2):148-156.

37. Oberoi SS, Dhingra C, Sharma G, Sardana D. Antibiotics in dental practice: how justified are we. Int Dent J. 2015 Feb;65(1):4-10.

38. Berman LH, Hargreaves KM. Cohen's Pathways of the Pulp, 12th Edition. St. Louis: Elsevier, 2020

39. Alattas HA, Alyami SH. Prescription of antibiotics for pulpal and periapical pathology among dentists in southern Saudi Arabia. J Glob Antimicrob Resist. 2017 Jun;9:82-84.

40. Alonso-Ezpeleta O, Martin-Jimenez M, Martin-Biedma B, Lopez Lopez J, Forner-Navarro L, Martin-Gonzalez J, et al. Use of antibiotics by spanish dentists receiving postgraduate training in end odontics. J Clin Exp Dent. 2018 Jul 1;10(7):e687-e695.

41. Font-Vizcarra L, Tornero E, Bori G, Bosch J, Mensa J, Soriano A. Relationship between intraoperative cultures during hip arthroplasty, obesity, and the risk of early prosthetic joint infection: a prospective study of 428 patients. Int J Artif Organs. 2011 Sep;34(9):870-5.

42. Tolentino Ede S, Centurion BS, Ferreira LH, Souza AP, Damante JH, Rubira-Bullen IR. Oral adverse effects of head and neck radiotherapy: literature review and suggestion of a clinical oral care guideline for irradiated patients. J Appl Oral Sci. 2011 Oct;19(5):448 54.

43. Mansour H, Feghali M, Saleh N, Zeitouny M. Knowledge, practice and attitudes regarding antibiotics use among Lebanese dentists. Pharm Pract (Granada). Jul-Sep 2018;16(3):1272.

44. Ellervall E, Bjorklund F, Rohlin M, Vinge E, Knutsson K. Antibiotic prophylaxis in oral health care: administration strategies of general dental practitioners. Acta Odontol Scand. 2005 Nov;63(6):321-9.

45. Suda KJ, Calip GS, Zhou J, Rowan S, Gross AE, Hershow RC, et al. Assessment of the Appropriateness of Antibiotic Prescriptions for Infection Prophylaxis Before Dental Procedures, 2011 to 2015. JAMA Netw Open. 2019 May 3;2(5):e193909 